\title{
Shaping of Ceria-Based SOC Cells: Development of a Combined Tape-Casting and Infiltration Route
}

\author{
L. Guesnet ${ }^{\mathrm{a}, \mathrm{b}}$, P-M. Geffroy ${ }^{\mathrm{b}}$, A. Flura ${ }^{\mathrm{a}}$, C. Nicollet ${ }^{\mathrm{a}}$, \\ J-C. Grenier ${ }^{\mathrm{a}}$, J. Vulliet ${ }^{\mathrm{c}}$, T. Chartier ${ }^{\mathrm{b}}$ and J-M. Bassat ${ }^{\mathrm{a}}$ \\ ${ }^{a}$ CNRS, Univ. Bordeaux, Bordeaux INP, ICMCB, UMR 5026, F-33600 PESSAC Cedex, \\ FRANCE \\ ${ }^{\mathrm{b}}$ CNRS, Institut de Recherche sur les Céramiques (IRCER), UMR 7315, Centre Européen de \\ la Céramique, 12 rue Atlantis, 87068 LIMOGES Cedex, FRANCE \\ ${ }^{\mathrm{c}}$ CEA, Centre d'études du Ripault, 37260 MONTS, FRANCE
}

\begin{abstract}
The present study is focused on the development of simple and low cost preparation of GDC10 $\left(\mathrm{Ce}_{0,9} \mathrm{Gd}_{0,1} \mathrm{O}_{1,95}\right)$ as electrolyte for Solid Oxide Cells operating at $600^{\circ} \mathrm{C}$. The main goal is to shape a single cell with porous/dense/porous GDC10 layers, the porous layers being thereafter infiltrated by catalysts. Two shaping methods are used. In the first one the electrolyte powder is pressed, followed by the infiltration of a screenprinted porous backbone. $\operatorname{Pr}_{6} \mathrm{O}_{11}$ and $\mathrm{Ni}$ were infiltrated as catalysts on the oxygen and hydrogen side, respectively. In both cases, the polarization values measured at $600^{\circ} \mathrm{C}$ on symmetrical cells are very low. To further facilitate the preparation of the cell, a porous/dense/porous support is elaborated in one step using tapecasting, then infiltrated with catalysts. The goal being to obtain a dense GDC10 electrolyte with two porous GDC10 backbones at the same temperature. Electrochemical measurements either on symmetrical or single cells are described.
\end{abstract}

\section{Introduction}

One of the critical challenges to the application and commercialization of SOC (Solid Oxide) Cells is their long-term stability (1). Several degradation processes have been reported from long time, which can depend on whether the SOFC or SOEC mode is considered. Among them, the main phenomena are i) the depletion and agglomeration of nickel which are visible in fuel electrodes ii) the diffusion of strontium from the air electrode towards the electrolyte (2). Moreover, in SOEC mode a demixing of the air electrode is often observed, as well as the formation of oxygen bubbles at the grain boundaries (3). The possible reversible use of SOC cells is also to be carefully considered (4).

An efficient way to limit the performance degradation is to operate the SOCs at reduced temperature $\left(500{ }^{\circ} \mathrm{C}<\mathrm{T}<600{ }^{\circ} \mathrm{C}\right)$. However, at such low temperatures the electrocatalytic activity of both air and fuel electrodes has to be increased, for instance by introducing highly active catalysts materials in an ionic conducting-based backbone by infiltration $(5,6)$, then preparing performing air and fuel composite electrodes. Infiltration is an effective approach to enhance the electrodes functionality because $i$ ) it produces nano-structured electrodes with enlarged surface areas, leading to efficient composite electrodes, ii) the technique usually requires lower temperatures than what is needed to sinter a screen-printed electrode, thus limiting the problems of cationic inter-diffusion between the cell components and iii) the ionic 
conductor that serves as a backbone generally possesses higher ionic conductivity that most of the considered electrodes, especially on the air side (7). Another point to consider is the thermomechanical compatibility between the electrolyte and the electrodes. For this purpose, our work focused on the same material possibly used as both electrolyte and ionic backbone. The choice of substituted-gadolinium ceria (GDC) seemed highly recommended with respect to its high ionic conductivity at reduced temperature. Finally, with respect to the degradation issues each infiltrated catalysts are single cationic and strontium free.

In this frame, the goal of this study is to build a single cell of porous/dense/porous GDC10 layers, the porous layers being thereafter infiltrated by catalysts. Two different simple and low cost cells shaping processes were developed, there are described, as well as the corresponding electrochemical measurements.

\section{Shaping Route ${ }^{\circ}{ }^{\circ}:$ Pressing Electrolyte Combined with Screen-Printing and Infiltration Electrodes}

\section{Cell Preparation}

The ionic conducting oxide considered in our study was the gadolinium doped ceria GDC10 $\left(\mathrm{Ce}_{0.9} \mathrm{Gd}_{0.1} \mathrm{O}_{2-\delta}\right)$ for its high ionic conductivity $\left(\sigma_{i}=0,0095{\mathrm{~S} . \mathrm{cm}^{-1}}^{-1} 500{ }^{\circ} \mathrm{C}\right)(8)$. A commercial powder provided by Solvay Company was uni-axially pressed into a green pellet of $25 \mathrm{~mm}$ diameter and $0,8 \mathrm{~mm}$ thickness. The pellets were sintered at $1500{ }^{\circ} \mathrm{C}$ during 3 hours to reach a relative density higher than $95 \%$. In a second step, a porous backbone of GDC10 and a current collecting layer were screen-printed on the electrolyte (in each case an ink containing pore forming agent (carbon) was prepared). The collecting layers were an iron-based perovskite oxide for the cathode $\left(\mathrm{LaNi}_{0.6} \mathrm{Fe}_{0.4} \mathrm{O}_{3-\delta}\right)$, and nickel oxide for the anode. The backbones were of $16 \mathrm{~mm}$ diameter and $20 \mu \mathrm{m}$ thickness. The backbones and collecting layers were sintered at $1150{ }^{\circ} \mathrm{C}$ for $1 \mathrm{~h}$ in air. In a third step, the catalysts were infiltrated in the backbones. On the oxygen side, the required catalyst was $\operatorname{Pr}_{6} \mathrm{O}_{11}(9)$. For this purpose, a concentrated solution of praseodymium nitrate was infiltrated until loading of the infiltrated material reaches about 30 wt. \% of the backbone. On the hydrogen side, the required catalyst was metallic nickel. The targeted weight ratio is increased to $\approx 60 \mathrm{wt}$. \% (i.e. as in the classical cermet Ni/YSZ cermet $(10))$.

In a final step, the two types of symmetrical cells were annealed at $600{ }^{\circ} \mathrm{C}$, under air for the oxygen electrode and $\mathrm{H}_{2} / \mathrm{H}_{2} \mathrm{O}$ for the fuel electrode, to obtain the desired catalysts. As an example, figure 1 shows a composite GDC- $\operatorname{Pr}_{6} \mathrm{O}_{11}$ cathode prepared by infiltration, where the $\mathrm{Pr}_{6} \mathrm{O}_{11}$ infiltrated phase homogeneously covers the porous GDC backbone. 

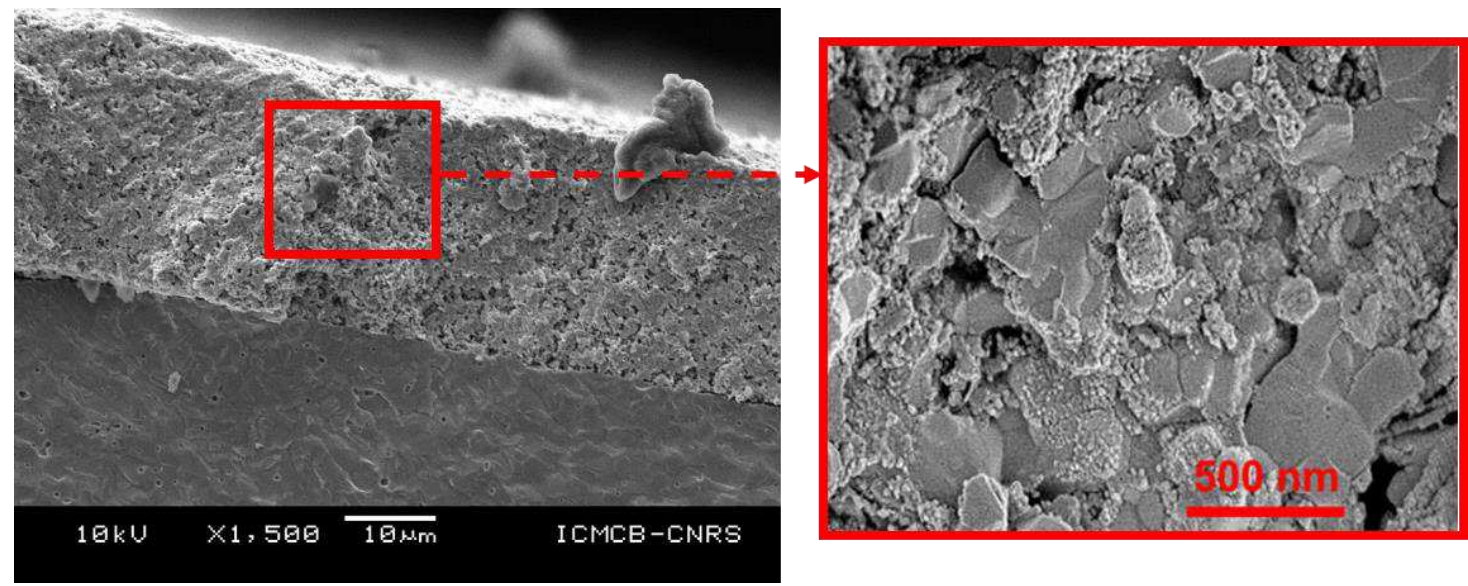

Figure 1. Cross section SEM image of a composite GDC- $\operatorname{Pr}_{6} \mathrm{O}_{11}$ cathode prepared by infiltration.

\section{$\underline{\text { Electrochemical Measurements on Symmetrical Cells (Oxygen Electrode) }}$}

The resistances of symmetrical cells were measured by impedance spectroscopy. The cells were placed between two gold grids supported by channeled alumina ceramics; a weight was applied to improve the current collection. The impedance diagrams were recorded every $50{ }^{\circ} \mathrm{C}$ between $400{ }^{\circ} \mathrm{C}$ and $600{ }^{\circ} \mathrm{C}$ in the frequency range $1 \mathrm{MHz}$ to $0.1 \mathrm{~Hz}$. The series and polarization resistances ( $R_{s}$ and $R_{p}$, respectively) were calculated from the impedance diagrams fitted using an equivalent circuit made of a series resistance and a combination of Gerischer and R-CPE equivalent elements.

The polarization resistance $R_{p}$ characterizes the electrode efficiency with respect to the involved reactions (oxygen and hydrogen sides). Different experimental parameters driving the infiltration can in fine modify the electrochemical performances of the cells. In this study, the solvent of the infiltration solution (water or ethanol) was changed. Figure 2a shows the evolution of $R_{p}$ as a function of temperature for two cells: one infiltrated with a water based solution, the second with an ethanol based solution. In both cases, the $R_{p}$ values are very low $\left(R_{p}=0,025 \Omega \cdot \mathrm{cm}^{2}\right.$ at $\left.600{ }^{\circ} \mathrm{C}\right)$, meaning that the electro-catalytic activity towards the oxygen reduction reaction is high, and that the solvent of the infiltration solution has a limited impact on the cell performance. A reference $R_{p}$ value of $0,15 \Omega . \mathrm{cm}^{2}$ at the operating temperature is generally considered, which is in this case achieved above $500{ }^{\circ} \mathrm{C}$.

The series resistance $R_{s}$ mainly characterizes the ionic conductivity of the electrolyte, according to relation [1]:

$$
\mathrm{R}_{\mathrm{s}}=\frac{1}{\sigma_{\mathrm{i}}} \cdot \frac{\mathrm{e}}{\mathrm{s}}
$$

However, an additional contribution to $R_{S}$ can appear when insulating phases are formed at the electrode/electrolyte interface (induced by chemical reactivity). Then, the experimental $R_{S}$ data were compared to those measured on a reference cell, i.e. a GDC10 dense pellet covered with platinum. Indeed, in this case, the interface contribution is negligible and the intrinsic ionic conductivity of GDC10 characterizes the reference cell. Consequently, when plotting the evolution of $\Delta R_{S}=R_{S}$ (cell) $-R_{S}$ (ref) as a function of temperature (Figure $2 \mathrm{~b}$ ), one is able to conclude if the interfaces are a brake or not for the electrons path between the electrolyte and 
the electrolyte. Figure $2 \mathrm{~b}$ shows the $\Delta R_{S}$ as a function of temperature for the cells prepared with a water based and an ethanol based infiltration solution. As required above $500{ }^{\circ} \mathrm{C}$ there is no additional contribution to $R_{s}$, the interface GDC10/electrode being even improved when compared to GDC10/Pt for $\mathrm{T}<500{ }^{\circ} \mathrm{C}$. Finally, the studied cells have sufficient electronic conductivity.

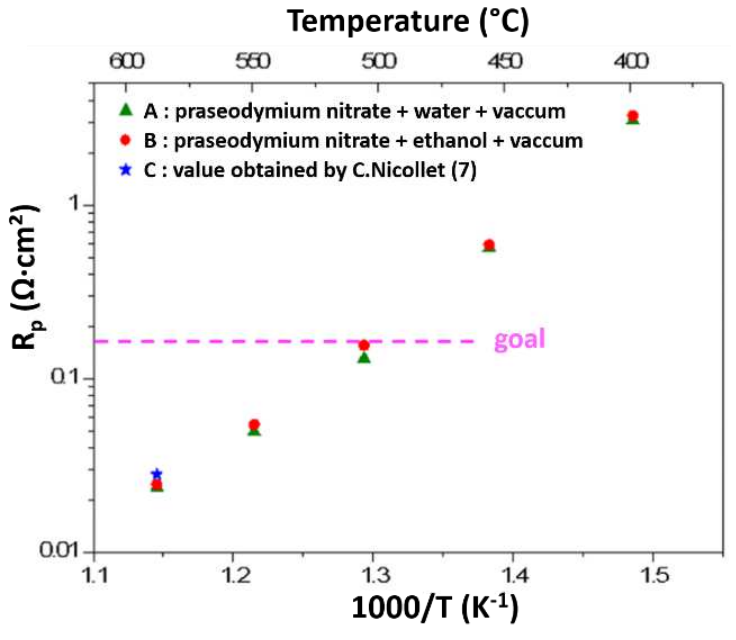

a)

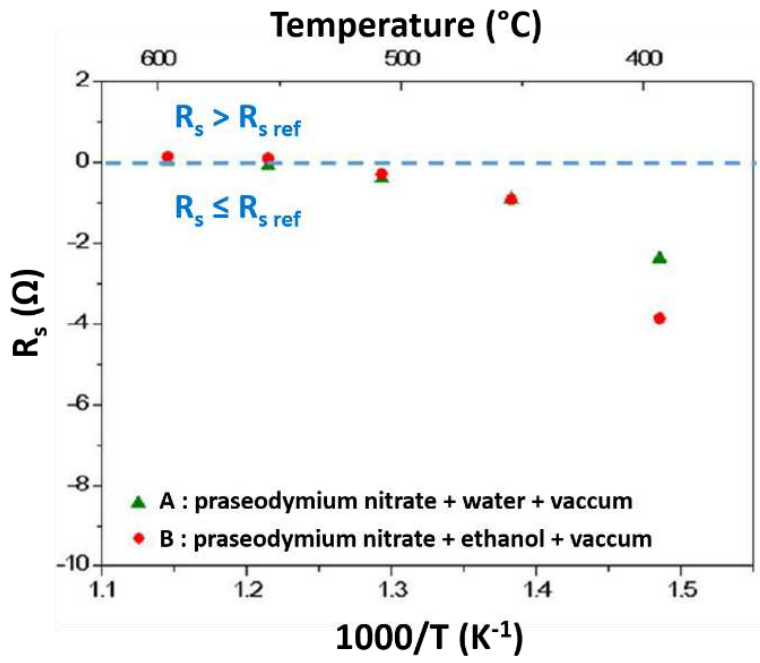

b)

Figure 2. Arrhenius plots of polarization (a) and series (b) resistances measured on symmetrical cells infiltrated with praseodymium nitrate using two different solvents; in the latter case, the $R_{s}$ value is compared to the one of the reference cell.

\section{Preliminary Measurements on Single Cells}

The GDC10- $\operatorname{Pr}_{6} \mathrm{O}_{11}$ composite oxygen electrode was deposited on a CEA-made anodesupported half-cell (Ni-YSZ//8YSZ//GDC $\mathrm{BL}_{\mathrm{BL}}, \mathrm{GDC}_{\mathrm{BL}}$ being a dense barrier layer protecting the YSZ electrolyte), in the same way as described above. Preliminary measurements in both SOFC and SOEC modes were performed at $800{ }^{\circ} \mathrm{C}$ and the results are plotted on figure 3 .

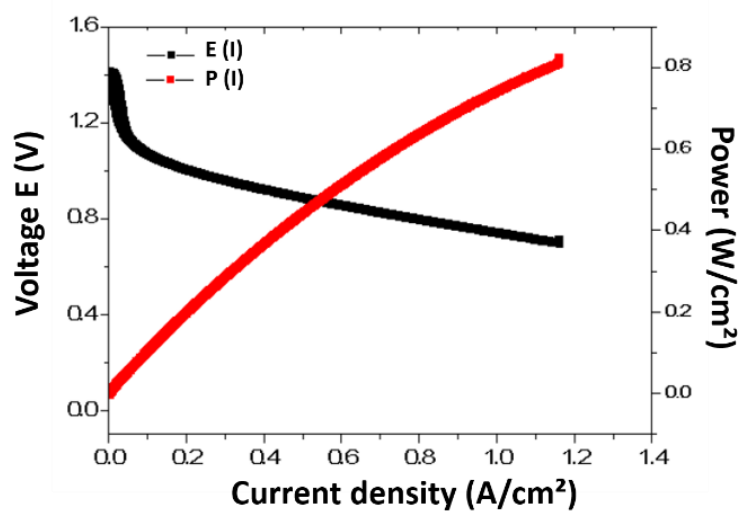

a)

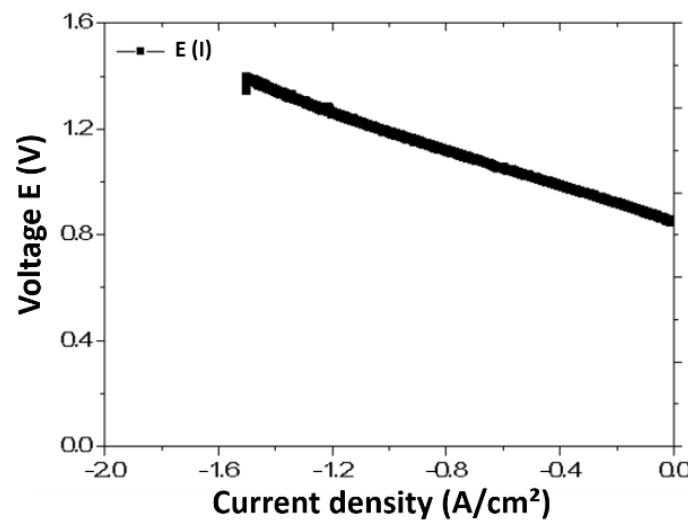

b)

Figure 3. Current density-voltage and power density curves recorded at $800{ }^{\circ} \mathrm{C}$ in either SOFC mode (3a) and SOEC mode (3b) using GDC10 skeleton infiltrated by $\operatorname{Pr}_{6} \mathrm{O}_{11}$ on a CEA-made anode-support half-cell. In both cases, the hydrogen flux was $24 \mathrm{NmL} / \mathrm{min} \mathrm{cm}^{2}$ (pure $\mathrm{H}_{2}$ in SOFC mode or a $\mathrm{H}_{2} \mathrm{O} / \mathrm{H}_{2}=90 / 10 \%$ mixture in SOEC mode). 
In SOFC mode, the maximum power density reaches $0,8 \mathrm{~W} \cdot \mathrm{cm}^{-2}$ at $0,7 \mathrm{~V}$. In SOEC mode, for the thermo-neutral point $(1,3 \mathrm{~V})$ the current density is $-1,3 \mathrm{~A} \cdot \mathrm{cm}^{-2}$. This cell is efficient either in SOFC and in SOEC modes. Even if lower compared to reference cells (from CEA for instance, with LSCF as oxygen electrode), such preliminary measurements using infiltrated praseodymium oxide on the oxygen side are promising, and in good agreement with others performed in the original study of infiltrated $\operatorname{Pr}_{6} \mathrm{O}_{11}$ by our group (8). Further measurements will be done in the next future, especially at lower temperatures and also using the GDC-based supports currently developed (see "Shaping route $n^{\circ} 2$ " part below).

\section{$\underline{\text { Electrochemical Measurements on Symmetrical Cells (Hydrogen Electrode) }}$}

On the hydrogen side, the experimental parameter of interest was the porosity of the collecting layer, i.e. $30 \%, 45 \%$ and $65 \%$. Figure 4 a compares the polarization resistances of symmetrical cells with collecting layers of various porosities. Again, $R_{p}$ values of the cells are very low $\left(R_{p}=0,008 \Omega \cdot \mathrm{cm}^{2}\right.$ at $\left.600{ }^{\circ} \mathrm{C}\right)$ and the $R_{p}=0.15 \Omega \cdot \mathrm{cm}^{2}$ specification is met for $\mathrm{T}>$ $500{ }^{\circ} \mathrm{C}$. However, the polarization resistance increases when the porosity of the collecting layer decreases (especially for 30\%). A reduced porosity can limit the molecular diffusion of hydrogen in the electrode, thus decreasing the electrochemical performance. The porosity also affects the values of the series resistance: when the porosity is high $(65 \%)$, at low temperature the series resistance increases compared to the reference cell. On the contrary, $R_{S}<R_{S}$ (ref) for the less porous electrodes (fig. 4b). In the two latter cases, the electronic conductivity of the collecting layer is sufficient and the electrode performance is good in symmetric configuration.

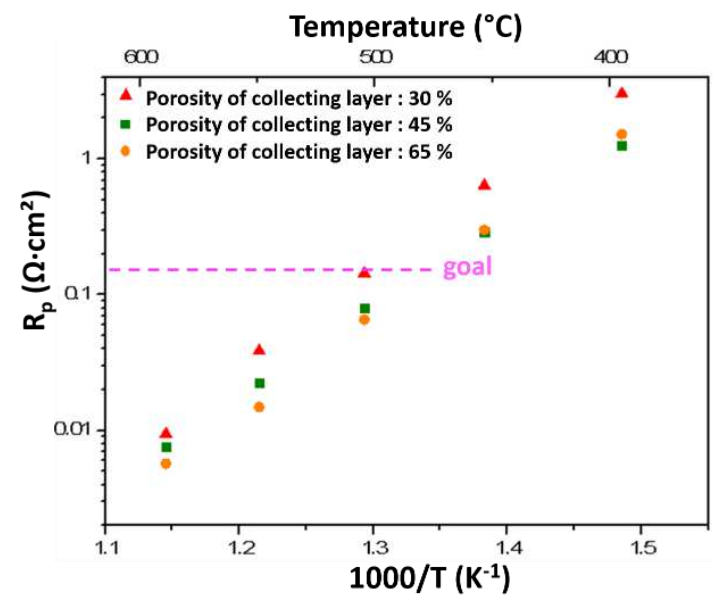

a)

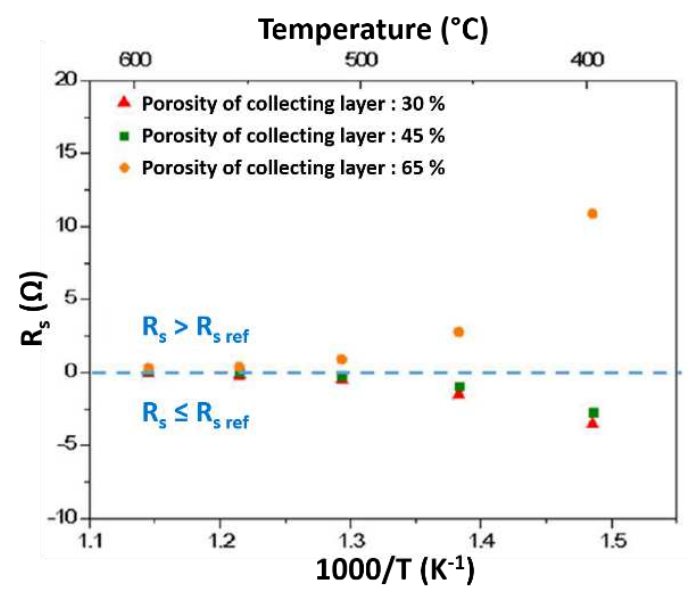

b)

Figure 4. Arrhenius plots of polarization (a) and series (b) resistances measured on symmetrical cells comparing the effect of the collecting layer porosity, nickel nitrate being infiltrated; in the latter case, the $R_{S}$ value is compared to the one of the reference cell.

Following this study performed on hydrogen electrodes, the porosity of the collecting layer for the next preparation steps was selected as a compromise between the optimization of the electronic conductivity (low porosity) and the efficiency of the electrode (high porosity), i.e. $45 \%$. 


\section{Shaping Route $\mathbf{n}^{\circ}$ 2: Porous/Dense/Porous by Tape-Casting Combined with Infiltration}

Thanks to the excellent electrochemical performances obtained on the symmetrical cells, both on the oxygen and hydrogen sides, the second step of this work was to develop an innovative preparation route, combining tape casting and infiltration.

\section{$\underline{\text { Cell Preparation }}$}

The motivation to use tape casting is to elaborate a thin GDC10 porous/dense/porous support in one-step, with an adjustable porosity in the backbone part. The main experimental parameters are the composition of the suspension and the pore-formers amount in the backbone part. Correlatively, the sintering temperature has to be optimized to fully densify the electrolyte part while keeping a sufficient porosity in the backbone.

The suspension includes several organic additives to prepare homogeneous green tapes without cracks, which can be easily handled. MEK/Ethanol azeotropic mixture was used as solvent. A dispersant is mandatory to lead to a satisfactory dispersion of the ceramic powder in the solvent. A binder gives the mechanical cohesion to the thin green tape, while a plasticizer makes it flexible, after the solvent evaporation. A phosphate ester was used as dispersant, an acrylic resin as binder and DBP (dibutylphthalate) as plasticizer (10-12). Carbon particles of about 1,6 $\mu \mathrm{m}$ diameter are introduced as pore forming agent to adjust the porosity of the porous backbone. Approximately 80 vol. \% of carbon pore former, with respect to GDC10 powder, were added in the corresponding suspension ( $c f$. Table 1). After homogenization, the slurries were tape-casted with a green thickness of approximately $100 \mu \mathrm{m}$. After drying, the green tapes were cut into $25 \mathrm{~mm}$ diameter disks, then several disks were stacked and laminated at $100{ }^{\circ} \mathrm{C}$ under $54 \mathrm{MPa}$ to obtain the required thickness of about $400 \mu \mathrm{m}$. The green stacks were then debinded at $800{ }^{\circ} \mathrm{C}$ to remove organic additives, and finally sintered at high temperature (around $1500{ }^{\circ} \mathrm{C}$ ).

Figure 5a shows a cross section of a tape-casted cell architecture prior to the infiltration step. The relative density of the electrolyte is about $98 \%$ while the backbone's porosity is $38 \%$, which is in the same range than obtained by the screen-printing (route $1-45 \%$ ). The final step was the infiltration of the tape-casted support by praseodymium nitrate as previously described. Table 1 summarizes the different experiments.

TABLE I. Sintering temperature of the tape-casted samples: pore formers amount and the porosity of the backbone layer.

\begin{tabular}{cccc}
\hline Sample & Sintering T $\left({ }^{\circ} \mathbf{C}\right)$ & Pore formers amount (vol \%) & Backbone porosity $(\%)$ \\
\hline Pressing/screen-printing & 1150 & $-/ 70$ & $-/ 45$ \\
Tape-casting 1 & 1600 & 80 & 31 \\
Tape-casting 2 & 1500 & 80 & 38 \\
Tape-casting 3 & 1450 & 85 & $>40$ \\
Tape-casting 4 & 1450 & 85 & $>40$ \\
\hline
\end{tabular}

As a general comment the electrolyte layer of the studied samples is dense (relative density $>95 \%$ ) whatever the sintering temperature until down to $1450{ }^{\circ} \mathrm{C}$, as required for the application. As expected, the backbone porosity increases upon decreasing the sintering temperature of the support. At $T_{\text {sintering }}=1450{ }^{\circ} \mathrm{C}$, with a pore former amount of $85 \mathrm{vol} . \%$ the 
porosity of the backbone is higher than $40 \%$, i.e. close to the porosity of the previous screenprinted layer.

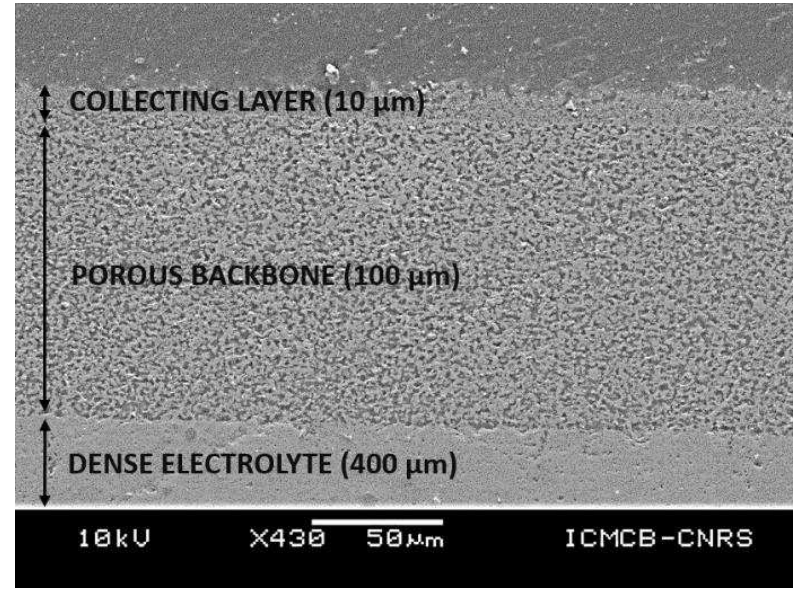

a)

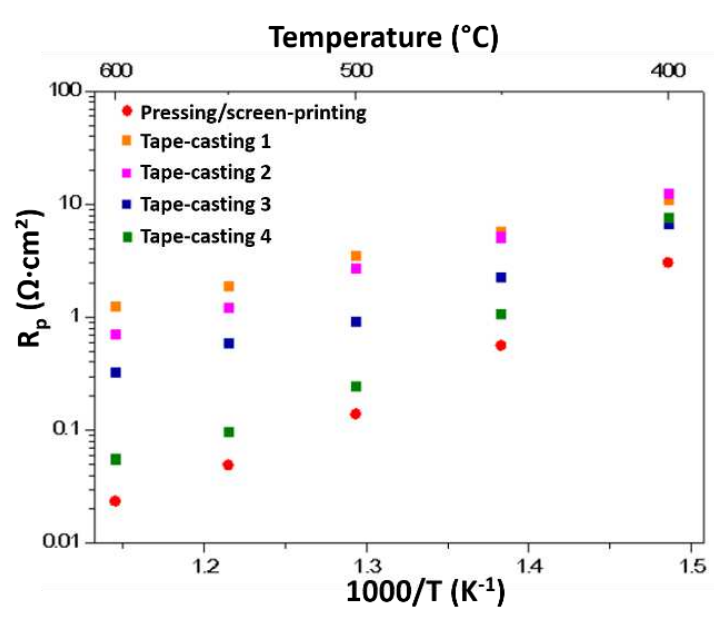

b)

Figure 5. (a) Cross section SEM image of a porous/dense/porous cell support of GDC10 prepared by tape-casting (tape-casting 2, cf. table 1) ; (b) Arrhenius plots of the polarization resistances determined on pressed / screen printed and tape-casted cells after a symmetrical infiltration of praseodymium nitrate solution and sintering.

\section{$\underline{\text { Electrochemical Performances }}$}

The electrochemical performances of the corresponding symmetrical tape-casted cells were measured after the praseodymium infiltration stage (as described in the first part). The Arrhenius plot of the corresponding $R_{p}$ values are shown on figure $5 \mathrm{~b}$ and compared to those determined on the pressed / screen-printed cell. The values of $R_{p}$ obtained on the tape casted cells are significantly higher than those of the cell prepared by pressing/screen-printing. However, for the cell named "tape-casting 4", the polarization resistance reaches $R_{p}=0.05$ $\Omega \cdot \mathrm{cm}^{2}$ at $600{ }^{\circ} \mathrm{C}$, which is promising for this preparation route.

One has to note that, in addition to the adjustment of the pore formers amount and the sintering temperature, various parameters were changed (nature of dispersants and bonders, nature of jars and balls for the milling ...). Indeed, because the polarization resistances of the tape casted cells are a bit higher than the pressed/screen printed ones, it is assumed that an additional resistive contribution still remains due to possible pollutions arising either from the organic compounds or from the milling conditions. Moreover, the electrode thickness of the electrode prepared by tape-casting is higher compared to screen-printing. Because, the electronic conductivity of $\operatorname{Pr}_{6} \mathrm{O}_{11}$ is limited, the ohmic drop may be more importante for such a thickness and consequently, may impact the polarization resistance $R_{p}$.

This work is currently in progress to remove the possible pollutions and to get the same $R_{p}$ values than those measured for the reference pressed/screen-printed cell. 


\section{Conclusions / Perspectives}

To operate Solid Oxide Cells (SOC) at reduced temperature $\left(500-600{ }^{\circ} \mathrm{C}\right)$ and increase their long-term stability, the choice of substituted-gadolinium ceria (GDC) as electrolyte is recommended with regard to its high ionic conductivity in this temperature range. In this context, the first goal of our work was to build a single cell made of porous/dense/porous $(\mathrm{P} / \mathrm{D} / \mathrm{P})$ GDC10 layers using the low-cost tape-casting route. Such architecture involving a single oxide is thermo-mechanically robust and is also able to be infiltrated by appropriate solutions on each porous side to prepare, in a second step, efficient oxygen and hydrogen electrodes at reduced temperatures.

In a first part of this work, in order to validate the concept, a first shaping route was considered, i.e. pressing of the dense GDC10 electrolyte, screen printing a porous GDC10 backbone on each side of the electrolyte, and infiltrating the catalysts solutions. Praseodymium and nickel nitrates were infiltrated with the aim to induce the crystallization of $\operatorname{Pr}_{6} \mathrm{O}_{11}$ at the oxygen electrode metallic nickel at the hydrogen electrode, respectively. The resistances of symmetrical cells were measured by impedance spectroscopy. The polarization resistance $R_{p}$ characterizes the electrode efficiency with respect to the involved reactions (oxygen and hydrogen sides). In both cases, the $R_{p}$ values are very low $\left(R_{p}=0,025 \Omega . \mathrm{cm}^{2} / 0,008 \Omega . \mathrm{cm}^{2}\right.$ at $600{ }^{\circ} \mathrm{C}$ for the oxygen and hydrogen electrodes, respectively), meaning that the electro-catalytic activity towards the oxygen /hydrogen reactions is sufficient. Moreover, the screen-printed GDC10-backbone infiltrated with $\operatorname{Pr}_{6} \mathrm{O}_{11}$ - oxygen electrode was deposited on a CEA-made anode-support half-cell (Ni-YSZ//8YSZ//GDC $\mathrm{GL}_{\mathrm{BL}}, \mathrm{GDC}_{\mathrm{BL}}$ being a dense barrier layer protecting the YSZ electrolyte), then annealed at $600{ }^{\circ} \mathrm{C}$. Even if the performance is lower compared to reference cells, such preliminary measurements using infiltrated praseodymium oxide on the oxygen side are promising.

In the second part, the tape-casting shaping technique was extensively developed as explained above. Several parameters of the tape-casting suspensions were optimized to successfully obtain, in a single sintering step, a dense GDC10 electrolyte, embedded between two GDC10 backbones with an appropriate porosity to allow the infiltration of the catalyst. The electrochemical performances of the tape-casted cells (after the praseodymium infiltration) stage) were measured. The performances obtained on the tape-casted cells are still lower than those shaped by pressing/screen-printing. Possibly, some pollutions remained at the GDC grain boundaries, arising from the tape-casting procedure. The up-coming work will be focused on this last issue, but currently the main goal of this innovative work has been reached.

\section{Acknowledgments}

This research was partly supported by a French regional fellowship "Région Nouvelle Aquitaine" (for L.G.). LG, JCG and JMB are grateful for financial support obtained throught the ANR project ECOREVE (ANR-18-CE05-0036-01). All the authors acknowledge the French grouping GDR HysPàc for fruitful discussions. Finally, the authors are grateful to the Solvay company (France) for providing the chemical precursors and powders used in this work. 


\section{References}

1. R. Knibbe, A. Hauch, J. Hjelm, S. D. Ebbesen and M. Mogensen, Green, 1, 14 (2005).

2. Q. Fang, C. E. Frey, N. H. Menzler and L. Blum, J. Electrochem. Soc., 165 (2), F38 (2018).

3. Q. Fang, L. Blum and N. H. Menzler, J. Electrochem. Soc., 162 (8), F907 (2015).

4. C. Graves, S. D. Ebbesen, S. H. Jensen, S. B. Simonsen and M. B. Mogensen, Nature, 14 (2), 239 (2015).

5. R. Cracium, S. Park, R. Gorte, J. Vohs and C. Wang, J. Electrochem. Soc., 146, 4019 (1999).

6. J. Vohs and R. Gorte, Advanced Materials, 21, 943-956 (2009).

7. A. Samson, M. Sogaard, R. Knibbe and N. Bonanos, J. Electrochem. Soc., 158, B650 (2011).

8. B. C. H. Steele, Solid State Ionics, 129, 95 (2000).

9. C. Nicollet, A. Flura, V. Vibhu, A. Rougier, J. M. Bassat and J. C. Grenier, Int. J. of Hydrogen Energy 41, 15538 (2016).

10. L. Pelegrini, J. Bastista Rodrigues Neto and D.Hotza, Rev. Adv. Mater. Sci. 46, 6 (2016).

11. J. Kiennemann, PhD thesis, University of Limoges (2004).

12. T. Chartier and P. Boch, Matériaux et processus céramiques, Hermes Science Publications, Paris (2001).

13. T. Chartier, Tape Casting, The Encyclopedia of Advanced Materials, eds D. Bloor, R. J. Brook, M. C. Flemings and S. Mahajan, Pergamon Press, 2763, Cambridge (1994). 